\title{
Equity Markets and the Performance of Hedge Funds: How stable is Persistence?
}

\author{
Prof. Dr. Pascal Gantenbein, Dr. Stephan Glatz, Prof. Dr. Heinz Zimmermann
}

\begin{abstract}
We investigate the performance of hedge funds in bull and bear equity markets. Covering the period from January 1994 to December 2008, we find that each bull and bear market period has its dominant independent variables. Furthermore, the level of performance persistence is not significantly related to equity market conditions. The analyses show that hedge fund performance persistence is stronger in more recent sub-periods than in earlier sub-periods. In bullish as well as in bearish equity markets, performance persistence is driven by both constant winners and losers. Moreover, both live and dead funds exhibit statistically significant levels of performance persistence.
\end{abstract}

Index Terms-equity markets; hedge funds; performance measurement; performance persistence

\section{INTRODUCTION}

$\mathrm{H}$ EDGE FUNDS are typically expected to generate positive returns irrespective of the directions of overall financial markets. In this regard, hedge fund performance relies, at least to a certain extent, on the managers' skills, experience and trading strategy. This paper analyzes the performance of hedge funds, focusing on the performance persistence of hedge funds during bull and bear equity markets. Based on a large sample obtained from Hedge Fund Research (HFR) database, we find no indication that hedge fund performance persistence is significantly related to equity market conditions. In fact, the results indicate that hedge funds exhibit performance persistence in both bear and bull equity markets. However, our results also show that performance persistence is significantly lower when equity market conditions change (i.e., from bull market to bear market or vice versa). Calculating rankings with respect to the relative levels of statistical significance among sub-periods, we find that the funds in more recent sub-periods exhibited higher levels of performance persistence than the funds in the earlier sub-periods. Furthermore, we find that performance persistence of live funds is primarily driven by constant winner funds, while persistence of dead funds is primarily driven by constant loser funds.

Manuscript received June 28, 2013

Prof. Dr. Pascal Gantenbein is full professor of Financial Management, University of Basel, Switzerland (e-mail: pascal.gantenbein@ unibas.ch).

Dr. Stephan Glatz is former Ph.D. student at the Henri B. Meier Department of Financial Management, University of Basel, Switzerland.

Prof. Dr. Heinz Zimmermann is full professor of Finance, University of Basel, Switzerland (e-mail: heinz.zimmermann@unibas.ch).
Our results document that the aggregate level of hedge fund performance persistence is largely independent of the equity markets but that some hedge funds perform significantly better or worse than their peers. Moreover, there is a momentum effect in hedge fund returns. As low levels of persistence in hedge fund performance often come along with changes in equity market conditions, winner hedge funds in bull markets do not necessarily remain winners in subsequent bear markets (or vice versa). In addition, we find evidence that constant loser funds exhibit a significantly higher probability of turning into dead funds. For these reasons, it is difficult to persistently generate outperformance relative to peers. As the dominant independent variables for explaining hedge fund performance change among the different sub-periods, our findings indicate alternating favorites across bull and bear markets.

While several studies provide evidence that hedge funds exhibit statistically significant levels of performance persistence (Agarwal and Naik [1]; Kosowski, Naik and Teo [2]; Eling [3]), only few studies have examined the relationship between performance persistence and financial market conditions. Capocci, Corhay and Hübner [4], for instance, conduct an analysis for a bullish sub-period (from January 1994 to March 2000) and a bearish sub-period (from April 2000 to December 2002). Using a ranking based portfolio approach, they find that predictability is strongest among middle performers during the bullish period, while there is no evidence for persistent winners during the bearish period. Capocci and Hübner [5] focus on performance persistence during the Asian crisis and find that the top performing funds in the year before the Asian crisis had significantly lower returns in the first year of the crisis. Furthermore, their results do not confirm performance persistence at yearly horizons, neither for the best nor for the worst performing funds, but they do give limited evidence for middle-decile funds. In contrast, the results of Jagannathan, Malakhov, and Novikov [6] show that performance persistence is strongly related to winner funds, while there is little evidence of persistence among loser funds. Edwards and Caglayan [7] do find evidence for performance persistence among winners and losers at the 12and 24-month time horizons.

In general, the results of empirical studies on hedge fund performance and persistence differ considerably, which is due to inconsistent data, methodologies, and investigation periods. In this context, several studies also emphasize the impact of data biases and investment trading restrictions. Baquero, Horst, and Verbeek [8] study performance persistence of hedge funds 
with a special focus on the look-ahead bias, for instance. Their results indicate that hedge fund attrition is mainly driven by historical returns, and that attrition rates are significantly higher for funds that performed poorly in the past. Similar to Baquero et al., Malkiel and Saha [9] document substantial backfill and survivorship biases in hedge fund data. Correcting for these biases, they note that hedge funds exhibit considerably lower returns than commonly supposed. Agarwal, Daniel, and Naik [10] find that managerial incentives and the degree of managerial flexibility are positively related to hedge fund performance. Moreover, they show that hedge funds with higher managerial incentives as well as funds with greater managerial flexibility are more likely to be persistent winners. Gantenbein and Glatz [11] find that accounting for the advance notice period of hedge funds has a severe negative impact on performance persistence, as the proportion of statistically significant persistent funds decreases considerably, especially for short-term time horizons.

Despite extensive research on the various aspects of the riskreturn persistence of hedge funds, little is known about its characteristics over time. In this respect, this paper differs from existing research in five key aspects: First, the investigation period covers a time period of 15 years including two bull and bear markets; second, the results are based on one of the largest samples ever used in academic research; third, beyond the all fund sample, the results are also reported for live and dead funds separately; fourth, the funds' performance is analyzed using contingency table-based methodologies; and fifth, subperiods are further divided into stable and transition periods. Thus, our paper introduces several key modifications with respect to previous studies and provides new empirical evidence on hedge funds performance persistence.

The remainder of this paper is organized as follows. Section II describes the methodological framework, while section III explains the data and descriptive statistics. Section IV presents the results and section $\mathrm{V}$ concludes this study.

\section{Methodology}

In order to measure hedge fund performance, we use a multifactor model containing a set of capital-market and alternative factors. Applying stepwise backward regression to the aggregate sample including all funds (ALLHF), the following six variables are selected: MSCI Emerging Markets (MSEM), excess return on equity market $\left(\mathrm{R}_{\mathrm{m}}-\mathrm{R}_{\mathrm{f}}\right)$, Barclays Capital Global High Yield (BCGHY), commodity market factor (GSCI), momentum factor (MOM), and size factor (SMB). The corresponding regression equation can be written as follows:

$$
\begin{aligned}
& R_{i t}=\alpha_{i T}+\beta_{i 1} M S E M_{t}+\beta_{i 2}\left(R_{m t}-R_{f t}\right)+\beta_{i 3} B C G H Y_{t} \\
& +\beta_{i 4} G S C I_{t}+\beta_{i 5} H M L_{t}+\beta_{i 6} M O M_{t}+\varepsilon_{i t}
\end{aligned}
$$

Hereby, MSEM mimics the equity market performance in international emerging markets, while $\mathrm{R}_{\mathrm{m}}-\mathrm{R}_{\mathrm{f}}$ provides a broadbased measure for U.S. equity markets. BCGHY covers a significant part of the international high-yield fixed income markets, and by including GSCI the variation of commodity returns is accommodated. With the size factor (SMB) and the momentum factor (MOM), predictors are included that are able to add explanatory power regarding potential time-series variations in equity market returns. Overall, the model builds on the classic factor models as suggested by Fama and French [12] and Carhart [13]. It is also similar to other models used in hedge fund performance evaluation such as, e.g., proposed by Fung et al. [14].

Similar to other studies (e.g., Agarwal and Naik [1]; Malkiel and Saha [9]; Bonadurer [15]; Eling [3]), the testing methodology for performance persistence is based on contingency tables. These are employed in statistics to analyze the relationship between two or more variables. In the context of hedge fund performance, contingency tables can be used to identify winner and loser funds. Winners (W) are those funds performing better than the median fund, while losers (L) are funds performing worse than the median fund, respectively. Using the (net) return for measuring performance, a hedge fund is described as being a winner, if it has a higher return in a specific period than the median return of all funds within the same strategy and period. Following this logic, four potential outcomes are possible: winner and winner (WW), winner and loser (WL), loser and winner (LW), and loser and loser (LL). Persistence is indicated when a winner (loser) fund in the first period is also a winner (loser) fund in the second period (WW or LL). When winner (loser) funds of the first period become loser (winner) funds in the second period (meaning WL or LW outcomes), this is an indication of missing persistence.

In general, we analyze the performance persistence at an aggregate fund level, meaning that the results of the individual funds (i.e., the number of WW, WL, LW, and LL outcomes) are pooled within a specific hedge fund strategy and presented on a hedge fund strategy-level. In other words, at an aggregate level, the outcomes of the individual fund's contingency tables flow into one pooled contingency table and are analyzed accordingly. Where $\mathrm{N}$ is the total number of observations (i.e., total number of WW, WL, LW, and LL), we use the following formula to calculate the chi-square statistic:

$$
X^{2}=\frac{(W W-D 1)^{2}}{D 1}+\frac{(W L-D 2)^{2}}{D 2}+\frac{(L W-D 3)^{2}}{D 3}+\frac{(L L-D 4)^{2}}{D 4}
$$

where

$$
\begin{aligned}
& D 1=\frac{(W W+W L)(W W+L W)}{N} \\
& D 2=\frac{(W W+W L)(W L+L L)}{N} \\
& D 3=\frac{(L W+L L)(W W+L W)}{N} \\
& D 4=\frac{(L W+L L)(W L+L L)}{N}
\end{aligned} .
$$

In order to determine the level of significance, the chi-square distribution with one degree of freedom is used. Thus, $X^{2}$ values that are greater than $2.71,3.84$, and 6.63 indicate 
significant persistence at the $10 \%-, 5 \%$-, and $1 \%$-confidence level, respectively.

As a second statistical methodology for testing performance persistence, the cross-product ratio (CPR) test is applied. The CPR shows the relationship's direction and its strength. In case of no persistence, each of the four categories WW, LL, WL, and LW should account for $25 \%$ of the outcomes. Hence, the null hypothesis of no performance persistence states that the $\mathrm{CPR}$ is equal to 1. Mathematically, the CPR is defined as follows:

$$
C P R=\frac{\left(W W^{*} L L\right)}{\left(W L^{*} L W\right)}
$$

The statistical significance of the CPR can be tested by using the Z-statistic. Hereby, the ratio of the natural logarithm of the CPR is divided by the standard error of the natural logarithm. For testing the statistical significance of performance persistence, Z-statistics with a value greater than $1.64,1.96$, and 2.58 indicate significance at the $10 \%$-, 5\%-, and 1\%-level, respectively. The $\mathrm{Z}$-statistic can be written as follows:

$$
Z=\frac{\ln (C P R)}{\sqrt{\frac{1}{W W}+\frac{1}{W L}+\frac{1}{L W}+\frac{1}{L L}}}
$$

For the investigation period used in our analysis (January 1994 to December 2008, i.e., 180 months), a maximum number of 179 observations per fund (with a 1-month time horizon) can be considered. Within this paper, four different time horizons are analyzed: monthly, quarterly, semi-annual, and annual horizons (1-, 3-, 6-, and 12-month horizons).

Dividing the investigation period of 180 months into bull market periods and bear market periods, the lengths of the subperiods are selected according to the equity market conditions using the Russell 2000 Index as a proxy. More specifically, the following periods are analyzed separately (1-month horizon): $01 / 1994$ to $02 / 2000$ (sub-period 1 or bull market I); $03 / 2000$ to $02 / 2003$ (sub-period 2 or bear market I); 03/2003 to $05 / 2007$ (sub-period 3 or bull market II); 06/2007 to 12/2008 (subperiod 4 or bear market II). Accounting for the specific end values related to the four different time horizons, the following additional sub-periods are created for testing performance persistence: 3-month horizon: (1) Q1 1994 to Q1 2000 (bull market I), (2) Q2 2000 to Q3 2002 (bear market I), (3) Q4 2002 to Q2 2007 (bull market II), (4) Q3 2007 to Q4 2008 (bear market II); 6-month horizon: (1) H1 1994 to H1 2000 (bull market I), (2) H2 2000 to H2 2002 (bear market I), (3) H1 2003 to H1 2007 (bull market II), (4) H2 2007 to H2 2008 (bear market II); 12-month horizon: (1) 1994 to 1999 (bull market I), (2) 2000 to 2002 (bear market I), (3) 2003 to 2006 (bull market II), (4) 2007 to 2008 (bear market II).

With the analysis of performance persistence, each subperiod is further divided into stable and transition periods. The transition period describes the breakpoint between two market conditions (e.g., the change from a bull market to a bear market). Having formed four sub-periods in total, three transition periods are observable: bull market I / bear market I (transition period I), bear market I / bull market II (transition period II), and bull market II / bear market II (transition period III). By focusing on these transition periods, it is possible to provide information on performance persistence when the general market regime changes. In contrast, stable periods only use the data from periods with virtually no market changes.

\section{DATA}

We use data from IIedge Fund Research (IIFR) database. HFR is one of the most respected commercial hedge fund data vendors and is used in many academic studies (e.g., Liang [16]; Agarwal and Naik [17]; De Souza and Gokcan [18]; and Fung et al. [14]). The HFR database includes both on-shore and offshore funds and contains both single funds and fund of funds. Based on HFR's live and dead fund database, the data consists of 12,036 funds (6,585 live funds and 5,451 dead funds) in the period of January 1994 to December 2008. In general, HFR's strategy classification system distinguishes between five hedge fund strategies: Equity Hedge (EH), Event-Driven (ED), Macro (M), Relative Value (RV), and Fund of Funds (FOF).

From the original dataset, only those funds that meet all the following requirements are included in the final sample: (i) funds must have reported complete return data from the inception date up to the fund's extinction (for dead funds) or to the end of the investigation period (for live funds); (ii) funds must have reported assets under management of at least USD 10 million or the equivalent in local currency in their most recent reporting; (iii) funds must report monthly return figures net of all fees; (iv) funds must have at least 24 months of complete return history; and (v) funds must only appear once in the final sample. This filtering process leads to a final sample of 4,788 hedge funds used in this paper. Out of this remaining total, 2,846 are live funds and 1,942 are dead funds.

Table I shows the breakdown by the number of sample funds for each of the five hedge fund strategies. Equity Hedge (1,646 or $34.38 \%)$ and Fund of Funds $(1,439$ or $30.05 \%)$ represent the two most important strategies. Furthermore the live-to-dead fund ratio mirrors the attrition rates of the funds. Fund of Funds (1.70) and Macro funds (1.68) display substantially lower attrition rates than the other hedge fund strategies. The average live-to-dead fund ratio is 1.47 over the investigation period, corresponding to $59.44 \%$ live funds and $40.56 \%$ dead funds in the final sample.

TABLE I. IIEDGE FUND STRATEGIES

\begin{tabular}{|l|c|c|c|c|}
\hline $\begin{array}{l}\text { Hedge Fund } \\
\text { Strategy }\end{array}$ & $\begin{array}{c}\text { Total no. of } \\
\text { funds }\end{array}$ & Live funds & Dead funds & $\begin{array}{c}\text { Live-to-dead } \\
\text { fund ratio }\end{array}$ \\
\hline Equity Hedge & 1,646 & 966 & 680 & 1.42 \\
\hline Event-Driven & 419 & 232 & 187 & 1.24 \\
\hline Macro & 616 & 386 & 230 & 1.68 \\
\hline Relative Value & 668 & 356 & 312 & 1.14 \\
\hline Fund of Funds & 1,439 & 906 & 533 & 1.70 \\
\hline All Funds & 4,788 & 2,846 & 1,942 & 1.47 \\
\hline
\end{tabular}

This column tho shows the total number of finds. Column three and four display the number of 
live funds and dead funds, respectively. Column five reports the live-to-dead fund ratio which represents the relationship between the number of live and dead fund.

The average length of a fund's return data is 79.6 months (around 6.6 years). 25\% of the sample funds have a return history equal to or greater than 108 months, while $30 \%$ report for less than 36 months. In total, the sample funds provide 381,218 monthly returns. The return data show that unadjusted hedge fund performance is generally superior compared to most major equity market and bond market indices. The average mean return appears to be significantly higher for hedge funds than for equity market indices, for instance. Moreover, hedge fund returns exhibit negative skewness and excess kurtosis. In this respect, the risk-return characteristics are different among the five hedge fund strategies.

\section{RESUlts}

In this section, we present the results of the performance measurement and performance persistence analysis.

\section{A. Performance measurement}

Table II displays the R-square, the F-value, the constant (intercept), and the significant coefficients at the 5\%-level for the aggregate hedge fund samples over the four sub-periods. In general, the explanatory power of the six-factor model is relatively high. R-squared are between $75.37 \%$ and $92.26 \%$ for the all hedge fund sample (ALLHF). However, the values are higher for more recent sub-periods (bull market II and bear market II), and the explanatory power of the predictors is not constant over time. In fact, our results indicate that each subperiod has its dominant drivers. In the first sub-period (01/1994 to $02 / 2000)$, the excess return on equity market $\left(R_{m}-R_{f}\right)$ and the size factor (SMB) display the highest levels of significance and are strongly present in most hedge fund strategies (EH, ED, and FoF). The second sub-period $(03 / 2000$ to $02 / 2003)$ is dominated by the excess return on equity market $\left(\mathrm{R}_{\mathrm{m}}-\mathrm{R}_{\mathrm{f}}\right)$ and the global high yield index (BCGHY), while statistical significance in the third sub-period (03/2003 to 05/2007) is mainly driven by the emerging markets equity factor (MSEM). MSEM and the commodity market factor (GSCI) are the dominant factors in the fourth sub-period (06/2007 to 12/2008).

While the results for the five hedge fund strategies display some time-varying behavior, it is obvious that a combination of equity, fixed income, and commodity market factors are quite reliable and powerful predictors of hedge fund returns. The only exception is the case of Macro funds, the performance of which cannot be adequately explained by the six-factor model. Obviously, Macro funds do not have a strong directional exposure to the traditional asset classes and therefore offer a different risk-return profile.

The decreasing constant (intercept) over time (e.g., from $0.93 \%$ over $0.75 \%$ and $0.39 \%$ to $-0.26 \%$ for ALLHF) indicates that hedge funds' abilities to generate superior risk-adjusted returns decreased over time. Moreover, the intercept fluctuates considerably, potentially as a consequence of different levels of unidentified risk exposure and time-varying performance. Additionally, we find that the level of autocorrelation is not constant over time. The Durbin-Watson test shows that the returns exhibit positive serial correlation in sub-periods 1 to 3 , while there is even slightly negative serial correlation (DurbinWatson test of 2.32) in sub-period 4. However, no significant serial correlation of returns in sub-periods 1,2 , and 4 can be observed, in contrast to the observed serial correlation for subperiod $3(03 / 2003$ to $05 / 2007)$.

Overall, the results for the sub-periods confirm the findings of the entire investigation period. The null hypothesis that none of the variables are significant predictors needs to be rejected for the majority of cases. More specifically, over the entire investigation period of January 1994 to December 2008, all six parameters show statistical significance at the 5\%-level. In the ALLHF sample, the smallest P-values of the independent variables are displayed for $\mathrm{R}_{\mathrm{m}}-\mathrm{R}_{\mathrm{f}}, \mathrm{MSEM}$, and MOM, indicating a strong positive relationship between hedge funds and both global equity markets and momentum in returns.

\section{B. Performance persistence}

We find that at the aggregate level the sample funds exhibit performance persistence for all four analyzed time horizons. Furthermore, the percentage of individual funds exhibiting significant levels of performance persistence decreases with increasing time horizon. In fact, the proportion of persistent funds is highest at the 1-month horizon but lowest at the 12month horizon. In addition, we find no indication that the level of performance persistence is significantly related to the choice of performance measure, which we assessed using the return and Sharpe ratio separately. Regarding the test methodologies, the reported differences between the chi-square test and the cross-product test are insignificant at an aggregate fund level. Moreover, we find that live and dead funds exhibit different drivers of performance persistence. While persistence of dead funds is primarily driven by constant losers, persistence of live funds is mainly driven by constant winners. Both live and dead funds exhibit statistically significant levels of performance persistence over the investigation period of 15 years.

In a next step, we subdivided the investigation period into two bull and two bear market periods. Three measurement values are considered: (a) chi-square (X2) value, (b) crossproduct ratio (CPR) value, and (c) Z-statistic (Z) value.

Table III reports the aggregate results for the four subperiods at the 1-month horizon. Statistically significant levels of performance persistence can be found for all four subperiods. For example, the Z-statistic values range from 24.14 (01/1994-02/2000) to 58.41 (03/2003-05/2007). The WW and LL observations in each sub-period are more frequent than WL and LW. The minimum percentage of the subsumed persistent observations (WW and LL) is $55.03 \%$ (1-month horizon), for instance. Compared to the results of the entire investigation period, we find that sub-periods 1 and 2 (bull market I and bear market I) exhibit lower levels of persistence, while sub-periods 3 and 4 (bull market II and bear market II) exhibit higher levels of persistence, respectively. When using CPR-values as the ranking measure, the statistical significance increases from sub-period 1 to sub-period 3, while sub-period 4 exhibits a lower significance level than sub-period 3 but a higher level than sub-periods 1 and 2. Thus, performance persistence is stronger for the time after February 2003. 
TABLE II. REGRESSION ANALYSIS

\begin{tabular}{|c|c|c|c|c|c|c|c|c|c|}
\hline \multirow{5}{*}{ ALLHF } & & \multirow{2}{*}{\multicolumn{2}{|c|}{$\begin{array}{c}\begin{array}{c}\text { sub-period } 1 \\
(01 / 1994 \text { to } 02 / 2000)\end{array} \\
0.7801\end{array}$}} & \multirow{2}{*}{\multicolumn{2}{|c|}{$\begin{array}{c}\begin{array}{c}\text { sub-period } 2 \\
(03 / 2000 \text { to } 02 / 2003)\end{array} \\
0.7537\end{array}$}} & \multirow{2}{*}{\multicolumn{2}{|c|}{$\begin{array}{c}\begin{array}{c}\text { sub-period } 3 \\
(03 / 2003 \text { to } 05 / 2007)\end{array} \\
0.8351\end{array}$}} & \multirow{2}{*}{\multicolumn{2}{|c|}{$\begin{array}{c}\begin{array}{c}\text { sub-period } 4 \\
(06 / 2007 \text { to } 12 / 2008)\end{array} \\
0.9226\end{array}$}} \\
\hline & R-square & & & & & & & & \\
\hline & F-value (sig.) & 39.62 & $(0.0000)$ & 14.79 & $(0.0000)$ & 37.14 & $(0.0000)$ & 23.82 & $(0.0000)$ \\
\hline & Constant (std. error) & 0.0093 & $(0.0011)$ & 0.0075 & $(0.0011)$ & 0.0039 & $(0.0009)$ & -0.0026 & $(0.0025)$ \\
\hline & Sig. coefficients & MSEM, Rm-1 & BCGHY, SMB & Rm-Rf, BCG & & MSEM, BC & $\mathrm{Y}, \mathrm{SMB}$ & MSEM, GSC & \\
\hline \multirow{4}{*}{ EH } & R-square & \multicolumn{2}{|c|}{0.8954} & \multicolumn{2}{|c|}{0.8409} & \multicolumn{2}{|c|}{0.9074} & \multicolumn{2}{|c|}{0.9479} \\
\hline & F-value (sig.) & 95.62 & $(0.0000)$ & 25.55 & $(0.0000)$ & 71.88 & $(0.0000)$ & 36.41 & $(0.0000)$ \\
\hline & Constant (std. error) & 0.0111 & $(0.0011)$ & 0.0095 & $(0.0016)$ & 0.0047 & $(0.0009)$ & -0.0025 & $(0.0026)$ \\
\hline & Sig. coefficients & MSEM, Rm-1 & SMB & Rm-Rf, BCG & & MSEM, Rm- & BCGHY, SMB & MSEM, GSC & \\
\hline \multirow{4}{*}{ ED } & R-square & \multicolumn{2}{|c|}{0.7700} & \multicolumn{2}{|c|}{0.8059} & \multicolumn{2}{|c|}{0.7443} & \multicolumn{2}{|c|}{0.9552} \\
\hline & F-value (sig.) & 37.39 & $(0.0000)$ & 20.07 & $(0.0000)$ & 21.34 & $(0.0000)$ & 42.68 & $(0.0000)$ \\
\hline & Constant (std, error) & 0.0099 & $(0.0012)$ & 0.0070 & $(0.0012)$ & 0.0080 & $(0.0011)$ & -0.0035 & $(0.0020)$ \\
\hline & Sig. coefficients & Rm-Rf, BCG & , SMB, MOM & Rm-Rf, BCG & SMB & BCGHY, SN & & Rm-Rf, GSCl & \\
\hline \multirow{4}{*}{$\mathbf{M}$} & R-square & \multicolumn{2}{|c|}{0.0863} & \multicolumn{2}{|c|}{0.1530} & \multicolumn{2}{|c|}{0.6357} & \multicolumn{2}{|c|}{0.5184} \\
\hline & F-value (sig.) & 1.06 & $(0.3981)$ & 0.87 & $(0.5264)$ & 12.80 & $(0.0000)$ & 2.15 & $(0.1220)$ \\
\hline & Constant (std. error) & 0.0114 & $(0.0030)$ & 0.0087 & $(0.0034)$ & -0.0001 & $(0.0019)$ & 0.0035 & $(0.0047)$ \\
\hline & Sig. coefficients & - & & - & & MSEM, GSC & & - & \\
\hline \multirow{4}{*}{ RV } & R-square & \multicolumn{2}{|c|}{0.5404} & \multicolumn{2}{|c|}{0.7983} & \multicolumn{2}{|c|}{0.6104} & \multicolumn{2}{|c|}{0.9113} \\
\hline & F-value (sig.) & 13.13 & $(0.0000)$ & 19.13 & $(0.0000)$ & 11.49 & $(0.0000)$ & 20.55 & $(0.0000)$ \\
\hline & Constant (std. error) & 0.0092 & $(0.0009)$ & 0.0091 & $(0.0006)$ & 0.0057 & $(0.0006)$ & -0.0014 & $(0.0027)$ \\
\hline & Sig. coefficients & BCGHY, SM & & BCGHY, SM & & MSEM, BCC & & GSCI & \\
\hline \multirow{4}{*}{ FoF } & R-square & \multicolumn{2}{|c|}{0.7070} & \multicolumn{2}{|c|}{0.7109} & \multicolumn{2}{|c|}{0.7003} & \multicolumn{2}{|c|}{0.8898} \\
\hline & F-value (sig.) & 26.94 & $(0.0000)$ & 11.88 & $(0.0000)$ & 17.14 & $(0.0000)$ & 16.15 & $(0.0000)$ \\
\hline & Constant (std. error) & 0.0052 & $(0.0012)$ & 0.0039 & $(0.0008)$ & 0.0026 & $(0.0011)$ & -0.0052 & $(0.0030)$ \\
\hline & Sig. coefficients & Rm-Rf, BCG & , SMB, MOM & BCGHY, MC & & MSEM & & MSEM, GSC & \\
\hline
\end{tabular}

This table reports the R-square, the F-value, the constant (intercept), and the significant coefficients at the $5 \%$-level for the aggregate hedge fund samples over the four sub-periods. Abbreviations: ALLHF: all hedge fund sample; EH: Equity Hedge; ED: Event-Driven; M: Macro, RV: Relative Value, FOF: Fund of Funds; MSEM: MSCI Emerging Markets; Rm-Rf: excess return on the equity market; BCGHY: Barclays Capital Global High Yield; GSCI: S\&P GSCI Total Return Index; SMB: Small Minus Big factor; MOM: momentum factor.

The results for the 3-month and 6-month horizons are similar (not reported here for reasons of space). The results at the 6month horizon indicate that performance persistence is stronger in bear markets. For the 12-month horizon, all four sub-periods exhibit statistically significant performance persistence at the $5 \%$-level. However, with respect to the ranking among the four sub-periods, we find that bear market II (2007-2008) exhibits the lowest level of persistence, which is different from the shorter time horizons. Furthermore, the drivers of performance persistence are different between the sub-periods when using the 12-month horizon. More specifically, sub-periods 1 and 2 (1994-1999 and 2000-2002) are primarily driven by constant losers, while performance persistence of sub-period 4 (20072008 ) is primarily driven by constant winners, for instance. In sub-period 3 (2003-2006), performance persistence is driven by both constant winners and losers alike.

Regarding stable and transition periods, our results indicate that performance is more random at market breakpoints and statistically significant levels of persistence are less likely to occur. In contrast, the levels of performance persistence are higher within a general equity market trend than during periods of directional adjustment (from bull to bear market or vice versa). With respect to the financial crisis in bear market II, there is evidence of performance persistence at the 1-, 3-, and 6 -month horizons in the stable period. However, at the at 12month horizon the null hypothesis of no persistence cannot be rejected in the stable period, but has to be rejected in the transition period. In other words, the winner (loser) funds of
2007 are generally not the winner (loser) funds of 2008, but 2006 winner (loser) funds most likely also were 2007 winner (loser) funds. Obviously, during the financial crisis of 20072008, hedge funds were unable to consistently under- or outperform their peers over a yearly horizon.

For robustness checks, we ran the analyses for both live and dead funds separately. For all four sub-periods and for all four time horizons, both live and dead funds show statistically significant performance persistence at the $5 \%$-level on an aggregate basis. The results for the four sub-periods provide further evidence that dead funds are primarily driven by constant losers, in particular within sub-period 4 (bear market II). More specifically, in period $06 / 2007-12 / 2008,38.94 \%$ of all outcomes are LL among the dead funds at the 3-month horizon, for instance. This finding indicates that several funds exhibited constant negative performance in the financial crisis of bear market II and consequently had to leave the business (thereby becoming dead funds). Overall, we conclude that performance persistence is driven by constant losers (with dead funds) and constant winners (with live funds). Also with live funds and dead funds, the level of performance persistence is strongest for sub-period 3 (bull market II), confirming the finding of the all fund sample. Further, both live and dead funds generally display higher levels of persistence in stable periods than in transition periods. This also confirms the findings from the all fund sample. 
TABLE III. 1-MONTH TIME HORIZON

\begin{tabular}{|c|c|c|c|}
\hline \multicolumn{4}{|c|}{ 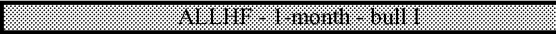 } \\
\hline $\begin{array}{l}\text { No. of obs. } \\
\% \text { of } \mathrm{N} \\
\% \text { of Col } \\
\% \text { of Row }\end{array}$ & Winner 2 & Loser 2 & \\
\hline Winner 1 & $\begin{array}{l}15,905 \\
\mathbf{0 . 2 7 4 8} \\
0.5498 \\
0.5501\end{array}$ & $\begin{array}{l}13,010 \\
\mathbf{0 . 2 2 4 8} \\
0.4493 \\
0.4499\end{array}$ & $\begin{array}{l}28,915 \\
0.4996\end{array}$ \\
\hline Loser 1 & $\begin{array}{l}13,022 \\
0.2250 \\
0.4502 \\
0.4495\end{array}$ & $\begin{array}{l}15,945 \\
\mathbf{0 . 2 7 5 5} \\
0.5507 \\
0.5505\end{array}$ & $\begin{array}{l}28,967 \\
0.5004\end{array}$ \\
\hline & $\begin{array}{l}28,927 \\
0.4998\end{array}$ & $\begin{array}{l}28,955 \\
0.5002\end{array}$ & 57,882 \\
\hline \multicolumn{4}{|c|}{ 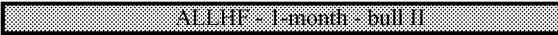 } \\
\hline $\begin{array}{l}\text { No. of obs. } \\
\% \text { of } \mathrm{N} \\
\% \text { of Col } \\
\% \text { of Row }\end{array}$ & Winner 2 & Loser 2 & \\
\hline Winner 1 & $\begin{array}{l}50,475 \\
\mathbf{0 . 2 8 5 2} \\
0.5704 \\
0.5695 \\
\end{array}$ & $\begin{array}{l}38,160 \\
\mathbf{0 . 2 1 5 6} \\
0.4311 \\
0.4305 \\
\end{array}$ & $\begin{array}{l}88,635 \\
0.5007\end{array}$ \\
\hline Loser 1 & $\begin{array}{l}38,018 \\
\mathbf{0 . 2 1 4 8} \\
0.4296 \\
0.4302\end{array}$ & $\begin{array}{l}50,356 \\
\mathbf{0 . 2 8 4 5} \\
0.5689 \\
0.5698\end{array}$ & $\begin{array}{l}88,374 \\
0.4993\end{array}$ \\
\hline & $\begin{array}{l}88,493 \\
0.4999\end{array}$ & $\begin{array}{l}88,516 \\
0.5001\end{array}$ & 177,009 \\
\hline \multicolumn{4}{|c|}{ XII } \\
\hline $\begin{array}{l}\text { No. of obs. } \\
\% \text { of } \mathrm{N} \\
\% \text { of Col } \\
\% \text { of Row }\end{array}$ & Winner 2 & Loser 2 & \\
\hline Winner 1 & $\begin{array}{l}20,443 \\
\mathbf{0 . 2 8 0 1} \\
0.5602 \\
0.5602 \\
\end{array}$ & $\begin{array}{l}16,051 \\
\mathbf{0 . 2 1 9 9} \\
0.4399 \\
0.4398 \\
\end{array}$ & $\begin{array}{l}36,494 \\
0.5000\end{array}$ \\
\hline Loser 1 & $\begin{array}{l}16,048 \\
\mathbf{0 . 2 1 9 9} \\
0.4398 \\
0.4398 \\
\end{array}$ & $\begin{array}{l}20,440 \\
\mathbf{0 . 2 8 0 1} \\
0.5601 \\
0.5602\end{array}$ & $\begin{array}{l}36,488 \\
0.5000\end{array}$ \\
\hline & $\begin{array}{l}36,491 \\
0.5000\end{array}$ & $\begin{array}{l}36,491 \\
0.5000\end{array}$ & 72,982 \\
\hline \multicolumn{4}{|c|}{ 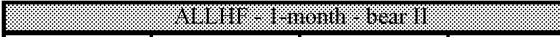 } \\
\hline $\begin{array}{l}\text { No. of obs. } \\
\% \text { of } \mathrm{N} \\
\% \text { of Col } \\
\% \text { of Row }\end{array}$ & Winner 2 & Loser 2 & \\
\hline Winner 1 & $\begin{array}{l}18,491 \\
\mathbf{0 . 2 8 2 8} \\
0.5658 \\
0.5636 \\
\end{array}$ & $\begin{array}{l}14,317 \\
\mathbf{0 . 2 1 9 0} \\
0.4378 \\
0.4364 \\
\end{array}$ & $\begin{array}{l}32,808 \\
0.5018\end{array}$ \\
\hline Loser 1 & $\begin{array}{l}14,190 \\
\mathbf{0 . 2 1 7 0} \\
0.4342 \\
0.4356\end{array}$ & $\begin{array}{l}18,383 \\
\mathbf{0 . 2 8 1 2} \\
0.5622 \\
0.5644 \\
\end{array}$ & $\begin{array}{l}32,573 \\
0.4982\end{array}$ \\
\hline & $\begin{array}{l}32,681 \\
0.4999\end{array}$ & $\begin{array}{l}32,700 \\
0.5001\end{array}$ & 65,381 \\
\hline
\end{tabular}

\section{CONCLUSION}

This study analyzes if hedge fund performance persistence is sensitive to the equity market environment. Based on the investigation period of January 1994 to December 2008, we find no indication that hedge fund performance persistence is significantly related to equity market conditions. However, we argue that the more recent sub-periods, in particular after 2002, exhibit higher levels of performance persistence than earlier sub-periods including both bull and bear markets. Furthermore, the levels of performance persistence are significantly higher when equity markets follow clear trends (stable periods) than when conditions change (transition periods).

Overall, our results document a significant persistence in hedge fund returns on an aggregate basis. Using a six-factor regression model, we were able to explain a considerable proportion (R-squared between $75.37 \%$ and $92.26 \%$ ) of the variation of hedge fund returns. However, the explanatory power of the predictors is not constant over time and depends on the hedge fund strategy. Our results indicate that each subperiod has its dominant drivers. Furthermore, in the recent past, the bandwidth between below-average and above-average performers was larger, which is likely to be the result of the increased number of hedge funds.

\section{REFERENCES}

[1] V. Agarwal and N. Naik, "Multi-Period Performance Persistence Analysis of Hedge Funds," Journal of Financial and Quantitative Analysis, vol. 35 (3), pp. 327-342, 2000.

[2] R. Kosowski, N. Naik, and Teo, "Do Hedge Funds Deliver Alpha? A Bayesian and Bootstrap Analysis,". Journal of Financial Economics, vol. 84 (1), pp. 229-264, 2007.

[3] M. Eling, "Does Hedge Fund Performance Persist? Overview and New Empirical Evidence," European Financial Management, vol. 15 (2), pp. 362-401, 2009.

[4] D. Capocci, A. Corhay, and G. Hübner, "Hedge Fund Performance and Persistence in Bull and Bear Markets," European Journal of Finance, vol. 11 (5), pp. 361-392, 2005.

[5] D. Capocci and G. Hübner, "Analysis of Hedge Fund Performance," Journal of Empirical Finance, vol. 11 (1), pp. 55-89, 2004.

[6] R. Jagannathan, A. Malakhov, and D. Novikov, "Do Hot Hands Persist Among Hedge Fund Managers? An Empirical Evaluation," Working Paper, 2007.

[7] F. Edwards and M. Caglayan, "Hedge Fund Performance and Manager Skill," Journal of Futures Markets, vol. 21 (11), pp. 1003-1028, 2001.

[8] G. Baquero, ter J. Horst, and M. Verbeek, "Survival, Look-Ahead Bias and the Persistence in Hedge Fund Performance," Journal of Financial and Quantitative Analysis, vol. 40 (3), pp. 493-517, 2005.

[9] B. Malkiel and A. Saha, "Hedge Funds: Risk and Return," Financial Analysts Journal, vol. 61 (6), pp. 80-88, 2005.

[10] V. Agarwal, N. Daniel, and N. Naik, "Role of Managerial Incentives, Flexibility, and Ability: Evidence from Performance and Money Flows in Hedge Funds". Working Paper, 2005.

[11] P. Gantenbein and S. Glatz, „The Impact of Advance Notice Periods on the Performance Persistence of Hedge Funds". Unpublished working Paper, 2010.

[12] E. Fama and K. French, "Common Risk Factors in the Returns on Stocks and Bonds," Journal of Financial Economics, vol. 33 (1), pp. 3-56, 1993.

[13] M. Carhart, "On Persistence in Mutual Fund Performance," Journal of Finance, vol. 52 (1), pp. 57-82, 1997.

[14] W. Fung, D. Hsieh, N. Naik, and T. Ramadorai, „Hedge Funds: Performance, Risk, and Capital Formation," Journal of Finance, vol. 63 (4), pp. 1777-1803, 2008.

[15] W. Bonadurer, "The Performance Persistence of Equity Long/Short Hedge Funds," Bern: Haupt, 2007.

[16] B. Liang, "On the Performance of Hedge Funds," Financial Analysts Journal, vol. 55 (4), pp. 72-85, 1999.

[17] V. Agarwal and N. Naik, "Generalised Style Analysis of Hedge Funds," Journal of Asset Management, vol. 1 (1), pp. 93-109, 2000.

[18] De Souza and S. Gokcan, "Hedge Fund Investing: A Quantitative Approach to Hedge Fund Manager Selection and De-Selection," Journal of Wealth Management, vol. 6 (4), pp. 52-73, 2004. 
Prof. Dr. Pascal Gantenbein, MRICS, is the HenriB.-Meier Professor of Financial Management at University of Basel's Center of Economic Sciences (WWZ). His academic activities are in the areas of corporate finance, portfolio management, risk management, real estate finance, and venture finance. He has been involved with many academic institutions worldwide and has also been working in the insurance sector and on real estate projects.

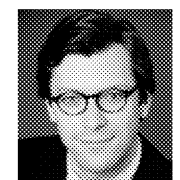

Dr. Stephan Glatz is a Senior Consultant with Roland Berger Strategy Consultants, a global management consultant firm. His primary areas of expertise include alternative investments, corporate \& investment banking, and asset \& wealth management. Previously, he used to work in the private equity and hedge fund business. His doctoral thesis was on the topic of performance persistence of hedge funds.

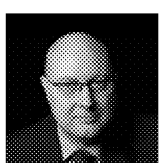

Prof. Dr. Heinz Zimmermann is a Professor of Finance at University of Basel's Center of Economic Sciences (WWZ). His research interests are in the field of empirical asset pricing and portfolio management. $\mathrm{He}$ is particularly interested in the application of quantitative models for tactical asset allocation decisions. Before his current position, he was a professor at the University of St. Gallen. 